\title{
Metalexicografia e parentesco
}

Metalexicography and kinship

Cristina Martins FARGETTI*

Universidade Estadual Paulista "Júlio de Mesquita Filho" (UNESP)

Lincon Luiz VANETI**

Universidade Estadual Paulista "Júlio de Mesquita Filho" (UNESP)

RESUMO: As línguas indígenas brasileiras têm recebido maior atenção da Linguística nos últimos anos, contudo, estamos longe de dar a elas um tratamento condizente com a necessidade de seu conhecimento e de sua documentação. Assim, no intuito de contribuir para o desenvolvimento da área, o grupo LINBRA tem realizado um amplo trabalho de pesquisa, cujos frutos têm surgido dentro de temáticas diversificadas. Este trabalho buscou contribuir para um projeto maior de construir um banco de dados do léxico de línguas indígenas de diversos campos semânticos, e também analisar a fragilidade sistemática do trabalho dos dicionaristas ao registrarem em suas obras complexos termos de parentesco de modo bastante inconsistente. Portanto, pretendemos contribuir para o conhecimento dos estudos nessa área específica, apontando possibilidades para novos caminhos.

PALAVRAS-CHAVE: Línguas indígenas. Banco de dados. Parentesco indígena.

ABSTRACT:.Brazilian indigenous languages have received an increasing attention from Linguistics in recent years, however, it is not suficiente in relation to the needs of their knowledge and documentation. Thus, in order to contribute to the development of the field, the LINBRA group has carried out an extensive research work, whose fruits have arisen within diverse themes. This work tried to contribute to a project of construction of a database of the lexicon of indigenous languages of diverse semantic fields, as well as to analyze the systematic fragility of the work of lexicographers by registering in their works complex terms of kinship

\footnotetext{
* Livre Docente em Línguas Indígenas (UNESP - 2015), Doutora em Linguística (UNICAMP - 2001). Atua como professora adjunta na Universidade Estadual Paulista "Júlio de Mesquita Filho" (UNESP), campus Araraquara, também atuando no Programa de Pós-Graduação em Linguística e Língua Portuguesa da mesma Instituição. Líder do Grupo LINBRA (Grupo de Pesquisas de Línguas Indígenas Brasileiras), pelo CNPq. cmfarget@gmail.com

** Mestrando no Programa de Linguística e Língua Portuguesa, UNESP, FCL-Ar. Graduado em Letras (2017) pela mesma universidade. Sua pesquisa de Iniciação Científica, que proporcionou a conclusão de sua monografia e subsidia parcialmente este texto, teve financiamento do CNPq, pelo projeto coordenado por Fargetti, Chamada Universal-2013, processo 477669/2013-1. 1lvaneti@ hotmail.com
} 
quite inconsistently. Therefore, we intend to contribute to the knowledge of studies in this specific area, pointing out possibilities for new paths.

KEYWORDS: Indigenous languages. Database. Indigenous kinship.

\section{Introdução}

Desde a publicação do livro de Rodrigues (1986), referência na área sobre as línguas brasileiras, que à época já chamava a atenção para a necessidade de se investigar o patrimônio linguístico nacional, muito já se fez e publicou. Há atualmente diversos centros de estudos no país em que as pesquisas sobre línguas indígenas vêm ocorrendo, apesar das dificuldades de financiamento, em particular. O grupo LINBRA ${ }^{1}$, sediado no campus de Araraquara da Unesp, tem se dedicado a tais pesquisas. Pensando maneiras de se abordar o léxico das línguas indígenas, Fargetti imaginou um levantamento em dicionários já existentes, com a possibilidade de se criar um banco de dados que contivesse, separadas por campos semânticos, palavras das mais variadas línguas indígenas brasileiras, no intuito de facilitar seu estudo comparativo. Isso foi iniciado com pesquisas de diversos discentes da Unesp, entre eles Vaneti (2017), que realizou seu trabalho sobre um conjunto de 24 obras, algumas de pesquisadores do SIL (Summer Institute of Linguistics) e as demais dissertações ou teses defendidas em universidades públicas brasileiras.

A intenção deste artigo é apresentar em parte o trabalho realizado, tendo em vista inclusive a proposta teórico-metodológica da "Terminologia Etnográfica" (FARGETTI, 2018) que aponta para estudos de campos semânticos específicos em dada língua, considerando-os partes de ciências, de saberes da cultura em que se inserem. Fargetti (op.cit.) questiona a noção de Ciência e sua relação com Cultura, portanto, e isso leva a olhar de forma diferente para o que possa ser Terminologia e sua aplicação em terminologias específicas. Pensando-se que Terminologia e Lexicografia podem, sim, caminhar de certa forma juntas, o que aqui se coloca então se insere em análise metalexicográfica, que parte de um questionamento Terminológico e Terminográfico.

\footnotetext{
${ }^{1}$ Grupo de Pesquisas de Línguas Indígenas Brasileiras, CNPq, liderado por Cristina Martins Fargetti
} 
Este texto se estrutura com um breve levantamento sobre as áreas dos estudos do léxico e de conceitos sobre parentesco na antropologia, para embasar uma análise de dicionários. Devemos dizer que, embora apresentemos questionamentos e críticas, como toda metalexicografia faz, não desmerecemos os trabalhos dos linguistas, pois sabemos das dificuldades para ir a campo, para enfrentar o estranhamento e mesmo o preconceito em relação a pesquisas com sociedades diferentes. Ao contrário, o que aqui se coloca são pontos para refletir, para repensar práticas de confecção de dicionários, muito comuns e talvez por isso nem sempre questionadas antes.

\section{Lexicografia e parentesco}

\subsection{Lexicografia e afins}

A área de Estudos do Léxico, na Linguística, tem se dividido em: Lexicologia, Lexicografia, Terminologia e Terminografia, com suas subdivisões. A primeira se refere a estudos buscando a constituição de palavras, suas formas, possibilidades de arquivamento e análise. Já a Lexicografia pode ser considerada a técnica de elaboração de dicionário, quer sejam vocabulários ou dicionários gerais, das mais diversas formas. A Terminologia se ocupa do estudo dos termos, considerados, em geral, palavras de uma língua com um sentido específico em uma área da Ciência; nesse sentido, a Terminografia é a técnica de elaboração de obras de descrição de termos. Obviamente, todas estas subáreas dialogam entre si, a ponto de haver questionamentos sobre a distinção entre elas, que ora é clara, ora é fluida.

O que nos concerne aqui é a Metalexicografia, que se ocupa da análise de dicionários, levando em conta diversos fatores, desde sua forma e suporte até a constituição de sua microestrutura.

Welker (2004) faz um apanhado de teorias da área e as apresenta ao leitor de modo a situá-lo melhor, dado que diferentes concepções do fazer lexicográfico ocorrem nos mais diversos meios. Com base em seu livro listamos a seguir alguns conceitos que estão na base de nosso trabalho:

1) Macroestrutura: o conjunto de entradas, que pode variar de número conforme o objetivo da obra; 
2) Microestrutura: as informações que compõem o verbete; a organização gráfica das informações deve ser a mesma em todos os verbetes;

3) Cabeça do verbete: compõe-se de todas as informações que antecedem as definições da entrada (a entrada também é conhecida por 'lema'); classe gramatical e variantes ortográficas são exemplos de informações que podem vir na cabeça do verbete;

4) Definição: grosso modo, trata-se da explicação, no corpo do verbete, sobre o que vem a ser a entrada; dicionários bilíngues, segundo nosso autor, não têm 'definições', mas 'equivalências';

5) Exemplo ou abonação: são exemplificações de como tal ou tal acepção do lema é usada; recomenda-se grafá-los em uma tipografia que os distinga do restante do texto no corpo do verbete; também se recomenda que estejam presentes em dicionários bilíngues e, nesse caso, que sejam extraídos de textos autênticos da língua fonte;

6) Remissão: quando o consulente é orientado a procurar outro verbete por sinonímia, antonímia ou porque há uma relação semântica; o aconselhável é que a remissão seja feita em via dupla, isto é, que X remeta a Y e Y remeta a X;

7) Equivalência: como já mencionado, na obra bilíngue não há definição, mas equivalência, que seria o modo, em língua alvo, de explicar a palavra da língua fonte em verdade, mesmo em dicionários monolíngues o que se tem são equivalências, dado que não existe sinonímia perfeita, como indica Welker (2004, p.29);

8) Metalíngua: em um dicionário bilíngue, consiste na língua utilizada para levar ao consulente as informações sobre a palavra que busca no verbete. A metalíngua, portanto, não é usada apenas na microestrutura, mas na macroestrutura também, pois muitas obras expõem informações relevantes em seções anteriores à macroestrutura propriamente dita.

O fazer lexicográfico (e também o terminográfico) leva em conta todas as partes de um dicionário, e também o conhecimento o mais acurado da estrutura da língua registrada. Assim, um lexicógrafo e um terminógrafo devem ter em mente questões sobre fonética e fonologia (ortografia, por exemplo), morfologia (segmentação das palavras, sua formação, sua classificação), sintaxe (classificação das palavras, abonações em sentenças bem formadas), semântica (equivalência possível e definições), discurso (relação língua e cultura), pragmática (o uso em contextos) (FARGETTI, 
2012). Isso torna um dicionarista um pesquisador atento a todos os níveis da língua que registra, e ora a obra tem características mais sintáticas, ora mais pragmáticas; ora se constitui obra enciclopédica.

\subsection{Parentesco}

As culturas humanas, apesar de sua grande diversidade, também apresentam elementos comuns. Um desses elementos comuns são os sistemas de parentesco, estruturas abstratas pelas quais os indivíduos se localizam socialmente. A posição dos indivíduos em tais sistemas é marcada por meio dos termos, que basicamente são palavras que se usa em referência àqueles considerados parentes, com relação a quem fala no momento. Os laços de parentesco podem ser de consanguinidade ou socialmente estabelecidos (no caso da adoção, por exemplo). Autores como Marie (1975), Ghasarian (1996) e Lévi-Strauss (1976) nos mostram que o assunto é amplamente estudado há cerca de 200 anos, com as mais diversas abordagens.

Para Lévi-Strauss (1976), os sistemas de parentesco marcam a divisão entre natureza e cultura, dado que a natureza seria caracterizada especialmente pelo caos, enquanto a cultura o seria pela ordem. As estruturas de parentesco seriam exclusividade humana (GHASARIAN, 1996), sistemas a organizar, dentro de uma sociedade, hierarquias, relações individuais vetáveis e não-vetáveis, regras de comércio, alianças militares entre povos e a vida espiritual da população. O parentesco desempenha, sobretudo nas sociedades ditas "tradicionais", um papel de suma importância: impõe uma série de recomendações atitudinais aos indivíduos cuja transgressão pode ser duramente castigada ou acarretar problemas de convivência, como ocorre com a proibição do incesto, por exemplo, ou com o modo correto de se tratar um parente mais velho.

É preciso ter em mente que os sistemas de parentesco, assim como a linguagem, são atributos intrínsecos dos humanos e que interferem em todas as esferas sociais. Assim, no estudo de uma língua indígena não se pode desprezar tais estruturas e suas implicações lexicais e culturais. Por isso Fargetti (2015) salienta que o pesquisador necessita de responsabilidade e acurácia quando da coleta dos dados em campo: fazer perguntas que levem em conta o contexto social para tentar obter respostas as mais 
completas possíveis. Também aponta que o linguista deva construir parcerias com pesquisadores de áreas afins, como antropólogos, no caso, para que estruturas da vida social possam ser cuidadosamente investigadas e registradas.

This means that a linguist, studying an endangered language, with almost no documentation and description, needs to make ethnographic research, in a dialogue with different areas, to achieve adequate knowledge about the lexemes he wants to describe in a dictionary. (FARGETTI, 2015: 138)

\section{Dicionários em discussão}

\subsection{Análise comparativa}

Nesta análise, por motivos de espaço, recuperamos a abordagem feita por Vaneti (2017) de um conjunto de apenas quatro obras: das línguas Apalaí (KOEHN \& KOEHN, 1995), Deni (KOOP \& KOOP, 2008), Paresí (ROWAN, 2001) e Rikbaktsa (TREMAINE, 2008). Apalaí é língua karib, falada no Pará; Deni é língua arawá, falada no Amazonas; Paresí é língua aruak, falada no Mato Grosso e Rikbaktsa é macro-jê, falada no Mato Grosso também. Todas as quatro obras analisadas têm em comum o fato de seus autores serem, à época de sua elaboração, filiados ao SIL.

Com exceção da obra sobre Apalaí, que propõe ao leitor um 'vocabulário', as outras três propõem 'dicionários'. As macroestruturas são semelhantes, apresentando capa, prefácio/introdução/apresentação, indicação de pronúncia dos vocábulos da língua indígena. Os verbetes estão arrolados em ordem alfabética em seções organizadas também em ordem alfabética (tanto no sentido L1>L2, quanto no sentido L2>L1 ${ }^{2}$ ). As obras Paresí e Deni apresentam gramáticas da língua antes das seções contendo os verbetes, enquanto Apalaí e Rikbaktsa não. Das quatro obras, apenas a Deni apresenta referências bibliográficas, nas quais não se encontra nenhuma menção a qualquer estudo antropológico sobre o povo Deni (o que naturalmente implica na qualidade e confiabilidade das informações ali registradas no tocante aos termos de parentesco). O

\footnotetext{
2 'L1' e 'L2' referem-se, respectivamente, à 'língua fonte' e 'língua alvo'. Trata-se de convenção terminológica dentro da lexicografia com fins de praticidade na escrita e economia de espaço.
} 
dicionário Rikbaktsa, por usa vez, é o único que traz um apêndice arrolando palavras por campos semânticos em seções separadas para cada um dos campos; tal apêndice localiza-se, na macroestrutura, como parte final, após a seção PB-LI²; a seção desse apêndice reservada ao campo semântico 'parentesco' simplesmente lista as palavras em LI seguidas de suas equivalências em PB. Em todas as obras tem-se o verbete, nos dois sentidos (L1>L2, L2>L1), organizados em duas colunas verticais.

Nenhuma das obras supracitadas parece ter sido escrita em parceria com outros especialistas. A ausência de bibliografia e a abordagem dispensada aos termos de parentesco reforçam essa impressão: não há, por exemplo, diagramas de parentesco que são úteis na identificação dos sistemas e no entendimento das relações descritas nos verbetes (quando descritas). Tais diagramas são abundantemente utilizados por antropólogos em seus trabalhos.

Quanto à microestrutura, selecionamos elementos que nos parecem indispensáveis em qualquer dicionário bilíngue - a saber: cabeça do verbete, equivalências, abonações, remissões e metalíngua - e os procuramos nas quatro obras no intuito de verificar a qualidade do material. Abaixo, duas tabelas para facilitar o entendimento:

Tabela 1: Elementos presentes ou ausentes nos verbetes no sentido LI-PB

\begin{tabular}{|c|c|c|c|c|c|c|}
\hline & $\begin{array}{c}\text { Lema } \\
\text { em } \\
\text { negrito }\end{array}$ & $\begin{array}{c}\text { Classe/ } \\
\text { inform. } \\
\text { gramatical }\end{array}$ & Equivalência & $\begin{array}{c}\text { Abonação } \\
\text { em } \\
\text { negrito }\end{array}$ & $\begin{array}{c}\text { Tradução } \\
\text { da } \\
\text { abonação }\end{array}$ & Remissão \\
\hline APALAÍ & $\square$ & $\square$ & $\square$ & ש & $\bar{\square}$ & $\square$ \\
\hline DENI & - & - & - & & & 口 \\
\hline PARESÍ & - & - & - & ש & 口 & 口 \\
\hline RIKBAKTSA & $\square$ & & - & ש & च & \\
\hline
\end{tabular}

Fonte: elaboração própria

\footnotetext{
2 'PB' e 'LI' significam, respectivamente, 'português brasileiro' e 'língua indígena'.
} 
Tabela 2: Elementos presentes ou ausentes nos verbetes no sentido PB-LI

\begin{tabular}{|c|c|c|c|c|c|c|}
\hline & $\begin{array}{c}\text { Lema } \\
\text { em } \\
\text { negrito }\end{array}$ & Equivalência & $\begin{array}{c}\text { Classe/ } \\
\text { inform. } \\
\text { gramatical }\end{array}$ & $\begin{array}{c}\text { Variante } \\
\text { em } \\
\text { negrito }\end{array}$ & $\begin{array}{c}\text { Equivalência } \\
\text { da variante }\end{array}$ & $\begin{array}{c}\text { Classe/ } \\
\text { inform. } \\
\text { gramat. } \\
\text { da } \\
\text { variante }\end{array}$ \\
\hline APALAÍ & - & - & च & & & \\
\hline DENI & - (s/ negrito) & 口 & & 口 & $\square$ & \\
\hline PARESÍ & a & - & - & - & - & - \\
\hline RIKBAKTSA & - (s/ negrito) & $\begin{array}{ll}\text { - } & (\mathrm{em} \\
\text { negrito })\end{array}$ & & & & \\
\hline
\end{tabular}

Fonte: elaboração própria

Observando-se as duas tabelas, percebe-se que, em cada língua, se o caráter sistemático da estrutura dos verbetes é respeitado em cada seção, não o é quando, em cada uma das obras, se passa de uma seção à outra: em todas as quatro obras, mudandose da seção LI-PB para a PB-LI, a estrutura do verbete visivelmente torna-se outra, fornecendo menos informações no sentido PB-LI. Os teóricos da lexicografia recomendam, conforme indica Welker (2004), que o autor seja sistemático na estruturação dos verbetes (tanto na cabeça do verbete quanto em seu enunciado lexicográfico), seja no sentido L1>L2, ou no L2>L1, pois seria uma maneira de se facilitar a leitura do consulente. Os autores dos dicionários, entretanto, seguiram à risca a prática de, mudando-se de seção e sentido, mudar a estrutura do verbete. Podemos questionar quais seriam as razões para isso, mas uma delas poderia ser a ideia de se evitar a repetição de formas e estruturas, pensando o autor que o leitor de um dos sentidos seria imediatamente leitor do outro, o que sabemos que não corresponde a toda consulta feita a um dicionário.

No respeitante às equivalências, percebe-se serem descuidadas com relação aos termos de parentesco. Quando há certa neutralidade e precisão antropológica na equivalência, colocando-se, para exemplificar, 'irmão da mãe' para 'tio' ou 'tio 
materno', erra-se por não haver indicação se se trata de termo referencial ou vocativo ${ }^{3}$, nem indicação de que com qual pessoa dentro do sistema está relacionado o tal 'irmão da mãe'. Em muitos sistemas, há, por exemplo, a distinção entre ego masculino e ego feminino, ou seja, como um homem menciona um parentesco pode ser totalmente diferente do modo de uma mulher. Tais indicações são preciosas para melhor se compreender o tipo de sistema de parentesco em questão, e, com isso, poder estabelecer comparações com outras culturas, o que é muito caro à Antropologia. Em verdade, a questão do parentesco é pobremente abordada pelas obras. É fato que não são todos os povos que tiveram sua cultura estudada por antropólogos, mas a omissão dos autores é patente, não havendo sequer alguma explicação sobre a metodologia que empregaram para a coleta dos dados ${ }^{4}$ e se tentaram algum levantamento bibliográfico a respeito do tema ou não.

As abonações, por tradição lexicográfica, vêm grafadas em tipografia diferente, são criadas pelo autor ou extraídas de corpus representativo e são aconselháveis quando o dicionário é voltado para produção textual, visto que exemplificam contextos de ocorrência do lema. Em todas as obras, o que observamos na verdade são exemplos descontextualizados, que não podem ser definidos como abonações por serem originados muito provavelmente de elicitação e não extraídos de banco de dados de textos escritos ou proferidos espontaneamente pelos usuários das línguas. São sentenças que questionamos se um dia poderiam ser proferidas pelo falante da língua, muitas vezes. Em sentido LI-PB, apenas as obras Apalaí, Paresí e Rikbaktsa apresentam exemplos em negrito seguidos de tradução. No sentido PB-LI, nenhuma apresenta exemplos, sendo Deni e Paresí as obras que trazem, no lugar, variantes em negrito seguidas das equivalências em português (não muito detalhadas); além disso, das duas, Paresí é a única que fornece informações gramaticais das variantes.

Em sentido LI-PB a única obra que não faz remissões é da língua Rikbaktsa. As outras satisfazem essa condição, porém de modo falho, pois ou a palavra remetida não está presente na macroestrutura ou está, mas sem fazer a remissão inversa, o que gera o problema de o consulente não travar conhecimento sobre uma das palavras. Explica-se:

\footnotetext{
3 'Termo referencial' seria aquele utilizado para se referir a alguém ausente do ato da conversação. 'Termo vocativo' seria aquele utilizado no ato do chamamento.

${ }^{4}$ Se fizeram com o informante uma genealogia prévia à coleta dos termos e se a utilizaram para sua coleta; se estiveram atentos à distinção entre homens e mulheres, por exemplo.
} 
se $\mathrm{X}$ remete a $\mathrm{Y}$, mas $\mathrm{Y}$ não a $\mathrm{X}$, tendo-se procurado, devido a contingências circunstanciais as mais diversas, primeiro por $\mathrm{X}, \mathrm{Y}$ será conhecido também, caso contrário, se as ditas contingências levarem a Y primeiramente, têm-se reduzidas as chances de se conhecer a X. E nenhuma das obras acrescenta remissões nos verbetes do sentido PB-LI. Novamente fica claro que os autores não seguem uma metodologia de apresentação das informações ou, antes, sobre quais informações serão sempre registradas. Não se pode esquecer que o recomendado, para maior praticidade e proveito do usuário, é que o que se decide por figurar em uma seção deva figurar na outra em se tratando de dicionários bilíngues com os dois sentidos, L1>L2 e L2>L1. E, levando em conta que sistemas de parentesco, como dito, podem ter diferenças entre ego masculino e ego feminino, as remissivas são essenciais nesse caso, porque o consulente pode então ampliar seu conhecimento e possibilidade de comparação.

Por último, há a metalíngua, que se recomenda figurar em ambas as línguas, a alvo e a fonte, dependendo do sentido da seção, ou apenas na alvo, que é a língua do público a que se dirige a obra. Os autores escolheram o português como metalíngua e, assim, mesmo no sentido LI-PB as poucas informações adicionais, quando aparecem, estão em português. Isso é criticável na medida em que os dicionários Apalaí, Paresí e Rikbaktsa afirmam explicitamente estar oferecendo uma obra de consulta tanto para não-indígenas quanto para indígenas, e estes últimos não têm o português como língua materna, embora possam gozar de bilinguismo devido à situação de contato com a sociedade caraíba. No caso Rikbaktsa, a obra nem sequer oferece uma lista com as abreviaturas usadas na microestrutura, algo que poderia facilitar a leitura de indígenas bilíngues, já que, como dito, o português é a metalíngua em ambos os sentidos nas obras estudadas, L1>L2 e L2>L1. Ao utilizar como metalíngua o português, os autores, contudo, não atentam para o fato de que não há sinonímia exata e que os equivalentes precisam ser descritivos, como aponta a Antropologia, em casos como "irmão da mãe" e não "tio".

Levando-se em conta que as quatro obras foram elaboradas por missionários, fica claro o objetivo de apresentação da língua para fins catequéticos. Diante disso, compreende-se porque são tão pouco detalhados os aspectos da cultura de tais povos, denotando não ter existido abordagem etnográfica mínima para conhecimento dos campos semânticos abordados. Aqui, enfocamos os termos do sistema de parentesco e 
verificamos a inadequação dos trabalhos, mas as abordagens de outros campos semânticos também poderiam receber as mesmas críticas. Lamentavelmente, muitas línguas indígenas do nosso país apresentam apenas dicionários como estes, quando contam com algum dicionário. Portanto, urge um estudo e documentação das línguas indígenas do país, e mesmo de línguas já estudadas por missionários poderiam ter outros dicionários, com abordagem teórica e metodológica diversa, e contando com objetivos científicos, de conhecimento de tais línguas e culturas, bem como com objetivos sociais, favorecendo revitalização e políticas linguísticas do interesse dos povos.

Para o trabalho com campos semânticos diversos, mesmo com o objetivo de obras lexicográficas, deve-se levar em conta o rigor de um trabalho terminológico, e, para o caso de culturas diversas da nossa, é necessário o trabalho etnográfico, como propõe Fargetti (2018), com a Terminologia Etnográfica:

\footnotetext{
Por lo tanto, al abandonar la compartimentación del conocimiento en ciencias de nuestra academia, tenemos la posibilidad de entender al otro con sus conocimientos, que pueden circunscribirse a otros dominios y no necesariamente a los nuestros; esto nos libraría del etnocentrismo al que he aludido anteriormente y nos permitiría ponernos en contacto con «saberes» no etiquetados como verdaderos o falsos desde la perspectiva de nuestra cultura. (FARGETTI, 2018, p. 357)
}

Assim, para podermos compreender o outro, com sua diversidade de pensamento, com sua específica relação língua-cultura, não nos resta outra saída além da etnografia, que nos permite deixar de lado o que nossa cultura compreende e classifica em ciências específicas, e nos leva a tentar compreender o outro a partir de suas classificações, de suas ciências, uma vez que contam com especialistas em saberes determinados.

\subsection{Exemplos de verbetes}

Para exemplificar o tratamento de um termo de parentesco, nas obras abordadas, citamos abaixo verbetes, os quais analisamos. Primeiramente, na obra da língua Apalaí. 
aja $(s)$ minha mãe veja: eny

eny $(s)$ baina; coldre; mãe aja, asa, jeny minha mãe, sua, dele

(KOEHN; KOEHN, 1995, p. 2 e 12)

$\mathrm{O}$ primeiro verbete traz a remissiva para o que apresentamos a seguir, e o consulente não compreende a relação existente entre ambos: não há relação semântica entre eles, apenas uma possível semelhança de formas entre eny "baina (sic!); coldre" e jeny "mãe dele". Mas não sabemos se aja, cujo equivalente é dado como "minha mãe", é termo de referência ou vocativo. Também não sabemos se ele se refere a ego masculino ou a ego feminino. Não há exemplos. Poderia ser dito que os autores não são antropólogos e que, por isso, não teriam tido condições de melhor abordar o assunto em trabalho de campo. Contudo, como a língua é karib, sabemos que estudos sobre os sistemas de parentesco entre comunidades de tal família existiam antes da publicação da obra, na década de 1990 (entre eles, por exemplo, Schwerin (1984)). Portanto, haveria conhecimento disponível na época de elaboração da obra lexicográfica para um melhor tratamento do assunto.

Abaixo, exemplos de verbetes da obra sobre a língua Deni:

abi (sm.) pai, termo vocativo e de referência. (V. ime'i, vava)

ime'i 1 (sm.) pai, i.e. genitor masculino, termo de referência (nunca usado para se referir ao próprio pai, mas somente ao pai de outro); genitor masculino de qualquer organismo biológico: humano, animal, peixe, inseto, planta, etc. 2 (adj. m.) grande, (fem: ime'eni, V. abi)

vava (sm.) pai, termo vocativo.

(KOOP; KOOP, 2008, p. 44, 60 e 95)

Nos verbetes acima, há falta de exemplos, falta de um mínimo tratamento antropológico dos dados, falta da metalinguagem da antropologia e sua tradução. Além disso, se ime'i, a remissiva de abi, se refere ao pai de outro que não Ego, isso não indicaria um sistema cindido? A segunda acepção apresentada para esse verbete não seria um caso de polissemia, mas sim de homonímia, portanto, não deveria constar do verbete e sim constituir nova entrada. Afinal, em que, semanticamente, o adjetivo 
"grande" se relacionaria a "pai"? E por fim, em que vava se relaciona com abi? Se ambos podem ser vocativos para "pai", o que os diferencia ou os aproxima? Note-se o problema com remissivas, referido anteriormente.

Para a língua Paresí, selecionamos os verbetes abaixo:

ekolatyasero s. (no-) mãe biológica; Hatyo atyo ekolatyasero. Foi ela que deu à luz a esta pessoa. (Veja kolatya levar.)

kolatya v. t. (na-) 1. carregar, levar; Kolatya babera enomana. Levou a carta para ele.

2. trazer; Kolatya babera nomani. Trouxe uma carta para mim.

(ROWAN, 2001, p. 14 e 50)

Para "mãe biológica", o lema apresentado aparece em exemplo cuja tradução o aproxima de uma função verbal e não nominal, como a classe de palavra referida (s. = substantivo): "Foi ela que deu à luz a esta pessoa". Acresce-se a esta impressão o que a remissiva nos aponta, ou seja, o verbo "carregar, levar", com semelhança formal com a anterior. Esse ponto não é elucidado, gerando mais dúvidas no consulente do que alguma certeza, com a remissão. Não há menção ao tipo de sistema de parentesco, não há detalhe antropológico.

Finalmente, para a última língua aqui focalizada, Rikbaktsa, o verbete abaixo:

je mãe. Sida je katsa batu taste bete hp ziky. A mãe de Cida não deixa ir com qualquer pessoa

(TREMAINE, 2008, p. 18)

O verbete, apesar de apresentar um exemplo, carece de informações de todo tipo.

As obras analisadas foram construídas por linguistas missionários, em época mais distante, com outros pressupostos e objetivos ${ }^{5}$. Para análises históricocomparativas, listas de palavras trazem contribuições para discussões fonológicas, morfológicas e sintáticas, apesar de não apresentarem sequer uma tentativa de

\footnotetext{
${ }^{5}$ As primeiras edições das obras analisadas são mais antigas que sua data de publicação on-line. Para a língua Paresí, 1978; para a língua Dení, 1985, para a línuga Apalaí, 1995. Para o Rikbaktsa, não temos a data da primeira edição, mas sabe-se que sua autora trabalhava com a língua na década de 1970.
} 
transcrição fonética. Contudo, mesmo tais tipos de estudos comparativos poderiam se beneficiar enormemente de detalhamentos maiores, permitindo melhores comparações, a nosso ver. Portanto, estas críticas pretendem contribuir para a elaboração de melhores obras lexicográficas e terminográficas.

Com o objetivo de levantamentos do que se produziu já em termos de dicionários de línguas indígenas é que foi iniciado o banco de dados da UNESP, elaborado por membros do grupo LINBRA. Em Fernandes et al (2018), damos informações sobre tal banco, sua constituição, sua forma de construção, metodologias empregadas, problemas encontrados e soluções obtidas pelos estudantes pesquisadores. Serviu como base para estudos já realizados por eles.

Se fazemos tantas críticas e considerações, poderia ser-nos perguntado como poderiam ser verbetes um pouco mais desenvolvidos? Fargetti (2015) aponta possíveis verbetes como os abaixo, para a língua Juruna, família Juruna, tronco Tupi:

-baba. n. [ 'bába ] (termo de referência e vocativo; identidade para ego masculino e feminino; consanguíneo). 1. F pai. baba wï "o pai chegou"; baba, atene wï "pai, venha logo" ; 2. FB irmão do pai (pã - termo em desuso, mas tido como mais tradicional) (cf. -pa)

-pa. n. [ pá ] (termo de referência; identidade para ego masculino e ego feminino; consanguíneo) 1. F pai. upa wï "meu pai chegou"; 2. FB irmão do pai (também -pa nana) 3. MH marido da mãe; 4. MZH marido da irmã da mãe -pa i'uraha. n. eFB irmão mais velho do pai. -pa iza. n. yFB irmão mais novo do pai (cf. baba)

(FARGETTI, 2015, p. 139)

Note-se que os lemas contam com transcrição fonética, em que os tons são marcados, assim como o acento de intensidade. A construção de cada verbete obedeceu a trabalho de campo realizado pela autora, que, apesar de ser linguista, revisou todos os dados da literatura antropológica disponível para sistema de parentesco do povo juruna (OLIVEIRA, 1970 e LIMA, 1995). Utilizou metalinguagem da antropologia, com o sistema internacional de abreviaturas ( $\mathrm{F}$ - father, FB - father's brother...), os quais foram traduzidos, o que antropólogos em geral não fazem. Diferenciou termo referencial de termo vocativo, bem como deu informações sobre distinção entre ego 
masculino e feminino. Deu abonações. Apresentou variantes. Cruzou remissivas. Contudo, apesar de tal detalhamento, faltam informações sobre a dinâmica social envolvendo os termos, o que ainda demanda maiores estudos, trabalhos etnográficos com revisões da literatura antropológica.

\section{Considerações finais}

Por razões históricas amplamente conhecidas, a colonização europeia do território hoje brasileiro conduziu um glotocídio. Rodrigues $(1986,2000)$ informa que, atualmente, o número de línguas indígenas não chega a 200, ao passo que, à época da chegada dos europeus, o número pudesse ser bem maior. Suas estimativas são consensuais, apresentando poucas e pequenas variações nos estudos publicados posteriormente. Consideramos um trabalho humanitário o de registrar as línguas indígenas, especialmente se atentarmos ao fato de serem também um patrimônio cultural humano. Chamamos a atenção, assim, para a necessidade de se conduzir pesquisas cuidadosas que atendam às demandas dos povos e que sigam metodologias claras da lexicografia e terminologia, e que não se faça mais proselitismo religioso, que não raras vezes toma carona na pesquisa linguística para operar seu conhecido estrago.

O que esperamos ter ficado claro ao longo do artigo é que se há um interesse crescente pelas línguas indígenas esse interesse deve ser cuidadoso e responsável. As obras analisadas põem em evidência uma displicência muito questionável: são livros feitos com conhecimentos indígenas mas que claramente servem apenas aos autores e leitores não-indígenas; são livros que se propõem como obras referenciais mas que falham em trazer informações completas e de confiança; são livros apresentados como dicionários, mas que não estão de acordo com as teorias lexicográficas mais aceitas na área, resultando em um material por vezes confuso para consulta.

Assim, há um longo percurso a enfrentar para termos obras lexicográficas e/ou terminográficas mais consistentes. Se isso é verdade para o que temos em línguas já há muito estudadas, como línguas europeias, para as línguas indígenas esse fato é ainda mais claro, levando-nos a pensar em alternativas para compreender culturas e línguas por vezes muito diferentes das nossas. E tais alternativas apontam para a abordagem etnográfica. 


\section{REFERÊNCIAS}

FARGETTI, C. M. Estudios del léxico de lenguas indígenas: ¿terminologia? In: GONZÁLEZ GONZÁLEZ, M; SÁNCHEZ-PALOMINO, M. D.; VEIGA MATEOS, I. (Orgs.) Terminoloxía: a necesidade da colaboración. Madrid: Vervuert, 2018, p. 343-368.

- Kinship and some lexicographic issues In: Planning non-existent

dictionaries.1 ed. Lisboa: Centro de Linguística da Universidade de Lisboa/Universidade de Aveiro, v.1, p. 134-142, 2015.

Dicionários de línguas indígenas e questões de prosódia. In: Cristina Martins Fargetti. (Org.). Abordagens sobre o léxico em línguas indígenas. Campinas: Editora Curt Nimuendajú, 2012.

FERNANDES, D.C.; MATEUS, I.D.; VANETI, L.L.; FARGETTI, C. M. Pesquisas lexicais de línguas indígenas: propostas metodológicas. In: FARGETTI, C. M. (org.) Léxico em pesquisa no Brasil. Araraquara: Letraria, 2018, p. 86-100.

GHASARIAN, C. Introdução ao estudo do parentesco. Lisboa: Terramar, 1996.

KOEHN, E. H.; KOEHN, S. S. Vocabulário básico Apalaí-Português: dicionário da língua Apalaí. Brasília: SIL Brasil, 1995. Disponível em: < http://www.oocities.org/br/indiosbrasileiros/apalaidc.pdf >. Acesso em: 13 mar. 2018.

KOOP, G.; KOOP, L. Dicionário Deni-Português. Anápolis: SIL Brasil, 2008, 149p. Disponível em: <https://www.sil.org/system/files/reapdata/69/34/93/6934937928986 5645463609429979398393103/DNDict.pdf >. Acesso em: 13 mar. 2018.

LÉVI-STRAUSS, C. As estruturas elementares do parentesco. Petrópolis: Editora Vozes, 1976.

LIMA, T. S. A parte do Cauim - etnografia juruna. Tese de doutorado, Rio de Janeiro: UFRJ, 1995. 
MARIE, A. Filiação, consanguinidade, alianças matrimoniais. In: AUGÉ, M. N. Os domínios do parentesco (filiação, aliança patrimonial, residência). Lisboa: Edições 70, 1975, p.13-20.

OLIVEIRA, A. E. Os índios juruna do Alto Xingu. Tese de doutorado, Dédalo, VI, 11, 12, São Paulo: USP, 1970.

RODRIGUES, A. D. Línguas brasileiras: para o conhecimento das línguas indígenas. SãoPaulo: Edições Loyola, 1986.

- Panorama das línguas indígenas da Amazônia. In: QUEIXALÓS, F.; RENAULT-LESCURE, O. (Org.). As línguas amazônicas hoje. São Paulo: ISA Socioambiental, 2000, p.15-28.

ROWAN, O. Dicionário Paresí-Português. Cuiabá: SIL Brasil, 2001, 120p. Disponível em: <http://www-01.sil.org/americas/brasil/publcns/dictgram/PCDict.pdf>. Acesso em: 28 abr. 2014.

SARDINHA, T. B. Linguística de Corpus: histórico e problemática. DELTA, São Paulo, v.16, n.2, 2000. Disponível em: <http://www.scielo.br/scielo.php? script=sci_arttext\&pid=S0102-44502000000200005\&lng=en\&nrm=iso\&tlng=pt $>$. Acesso em: 28 abr. 2014.

SCHWERIN, K. The kin-integration system among Caribs. Antropologica, 59-62, 1984. p. $125-153$.

TREMAINE, S. Dicionário Rikbaktsa-Português/ Português-Rikbaktsa. Cuiabá: SIL Brasil, 2007, 100p. Disponível em: < https://www.sil.org/system/files/reapdata/23/ 74/77/23747713988086297350702187859467170352/RKDic.pdf >. Acesso em: 13 mar. 2018.

VANETI, L. L. Banco de dados com termos de parentesco. Monografia de Final de Curso de Graduação. Araraquara: UNESP, 2017

WELKER, H. A. Dicionários: uma pequena introdução à lexicografia. $2^{a}$ edição revista e ampliada. Brasília: Thesaurus Editora, 2004. 